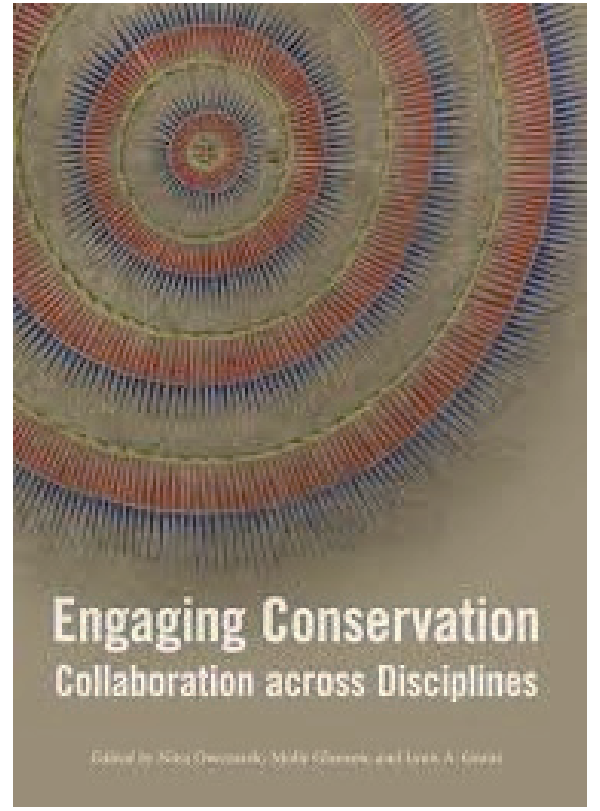

\section{Engaging conservation. Collaboration across disciplines}

\author{
Nina Owczarek, Molly Gleeson y Lynn Grant
}

London: Archetype Publications, 2018

ISBN: 9781909492554

Dimensiones: $210 \times 297 \mathrm{~mm}$

Páginas: 308
Publicación resultado de las conferencias de un simposio internacional realizado en el 2016 para conmemorar los 50 años de la creación del laboratorio de conservación del Penn Museum (Pennsylvania Museum of Archaeology and Anthropology).

Está dividido en 5 secciones dedicadas a la educación, la arqueología, las comunidades, las instituciones y la ciencia.

En la primera sección los profesionales de diversas instituciones exponen la estrecha relación que existió entre arqueología y los museos durante los años finales del s. XIX -principios de XX, destacando la comunicación sobre la nula visibilidad de las mujeres en las publicaciones sobre temas de conservación y arqueología en los inicios del siglo XX. Mujeres a la sombra de los científicos del British Museum que ponen en práctica o enseñan sus técnicas pero siempre supervisadas por ellos, dándonos una visión de género de los años de Petrie, Scott y Plenderleith y recordándonos que el desarrollo de la conservación como disciplina universitaria debe mucho a la mujer en aquellos primeros años.

También se reflejan la enseñanza de la conservación científica en el Museo Arqueológico John Hopkins de Baltimore y en el Center for the Analysis of Archaeological Materials (CAAM) dependiente de la universidad de Pensilvania, o el asesoramiento del Centro di Conservazione Archeologica de Roma para profesionales de países donde no hay mucho conocimiento de estos temas y el trabajo práctico de campo en el yacimiento etrusco de Poggio Colla, cerca de Florencia, Ilevado a cabo por un equipo de arqueólogos fundamentalmente norteamericanos.

En la segunda sección se abordan las excavaciones en Abydos, Egipto, en Gordion, Turquía o Morgantina, Sicilia llevadas a cabo por universidades americanas, las de Amara en Sudan del equipo del British Museum. o de Xian, China con datos sobre la conservación de los objetos y las oportunidades de prácticas e investigación sobre ellos.

El tercer apartado trata de la revitalización de distintas comunidades a través del estudio y conservación de sus objetos, depositados en los distintos museos: de los nativos americanos, los nativos de Alaska, del sitio inca de Aypate en Perú, África Central o del Oeste americano.

La cuarta sección se inicia con el proyecto de la digitalización de los objetos de la excavación de Ur realizada en 1927-1934 por Leonard Woolley. Este proyecto conjunto del Bristish Museum y el Penn Museum, tiene la esperanza de que en un futuro próximo se una el Iraq National Museum y consiste en el estudio y toma de datos de cerámicas, terracotas y metales de este yacimiento que han sido examinados, descritos, fotografiados y medidos y que ya están disponibles en una base de datos online.

Y finalmente en la quinta sección, la científica, se describen técnicas 3D para hacer reconstrucciones virtuales de por ejemplo la cratera de Eufronios o estudios comparativos de formulaciones con silanos para adobe, o análisis de vidrios de la excavación realizada por Petrie en Amarna. 
Esta obra, al tratar varias disciplinas, pero siempre con el hilo conductor de la arqueología puede resultar interesante tanto para todos aquellos que quieran saber más de los objetos descubiertos en las grandes excavaciones del XIX/XX, como para conocer el patrocinio de las instituciones en la realización de nuevas excavaciones, los estudios analíticos de obras o conjuntos muy representativos, sus intervenciones y sus resultados.

Emma García Alonso

Instituto del Patrimonio Cultural de España 